\title{
Performance Analysis and Simulation of a Three Phase Grid Tie Inverter
}

\author{
Jayashree $\mathbf{M}^{\mathbf{1}}$, Dr. Nagesh Prabhu ${ }^{2}$ \\ PG Scholar, Electrical and Electronics Engg., NMAM Institute of Technology, Nitte,India ${ }^{1}$ \\ Professor, Electrical and Electronics Engg., NMAM Institute of Technology, Nitte, India ${ }^{2}$
}

\begin{abstract}
This paper analyses the performance of a three phase grid tie inverter through simulation. The converter current controller is based on synchronous reference frame and $\mathrm{d}-\mathrm{q}$ transformation which provides the reference voltage signal for the desired converter output voltage. The Sinusoidal Pulse Width Modulation generates firing pulses for six MOSFETs of the three phase full wave bridge converter and inturn regulates the active and reactive power flow of the converter. The dynamic variation in the voltage of DC source is neglected and hence DC voltage is held constant. The DC bus current is controlled by varying active current reference $\mathrm{Iq}_{\mathrm{ref}}$. Accordingly the DC source can absorb or supply active power by varying $\mathrm{Iq}_{\mathrm{ref}}$ of the controller. The performance evaluation of three phase grid tie inverter for active power interaction while providing reactive power support is carried out in the present work.
\end{abstract}

Keywords: d-q transformation, Grid tie inverter, SPWM, MATLAB/Simulink.

\section{INTRODUCTION}

Now a days power demand is increasing day by day. In the present context, large number of renewable energy sources are being connected to the grid in view of managing the micro grid.To maintain constant voltage in the distribution system, VSC based converter is used when the renewable energy sources are connected at the DC bus. This paper discusses the effectiveness of control system of a three phase grid tie inverter through simulation results.

\section{STUDY SYSTEM}

The block diagram of study system is as shown in Fig.1. Synchronous reference frame phase locked loop is used to track the phase and frequency of the grid voltage. Grid voltage $\left(V_{\mathrm{g}}\right)$ and inverter current $\left(\mathrm{I}_{\mathrm{s}}\right)$ is converted into $\mathrm{d}-\mathrm{q}$ components by synchronous reference frame which is easily controlled by PI controller.Type1 controller is used to generate reference control signal.

Sinusoidal pulse width modulation is employed to compare reference control signal with high frequency carrier signal of about $40 \mathrm{KHz}$ to produce gating sequence for inverter switches. The dynamic variation in the voltage of DC source is neglected and hence DC voltage is held constant.

\section{III.DESIGN OF CONTROLLER}

To absorb active power from grid, inverter current must be in phase with grid voltage and to supply active power to the grid, inverter current must be out of phase with grid voltage.

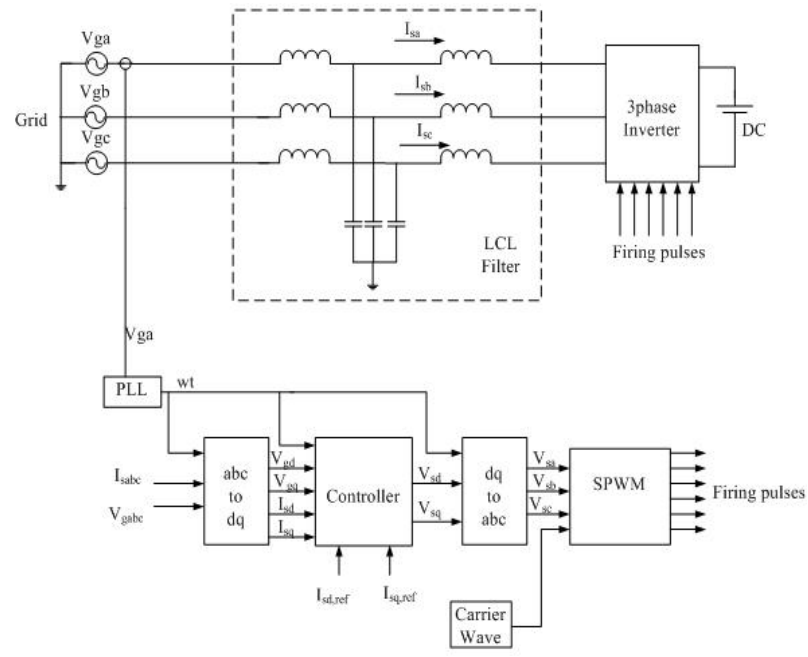

Fig.1.Block diagram of study system.

In a three phase grid tie inverter, grid voltage and inverter current are transformed to synchronous rotating reference frame (dq reference frame)using Kron's transformation[1]. Block diagram of generation of a control signal using rotating reference frame and Type 1 controller is as shown in Fig.2.

For three phase grid tie inverter voltage balance equation can be written as,

$$
\begin{aligned}
& V_{s d}=V_{g d}+V_{d}-\omega L I_{q} \\
& V_{s q}=V_{g q}+V_{q}-\omega L I_{d}
\end{aligned}
$$




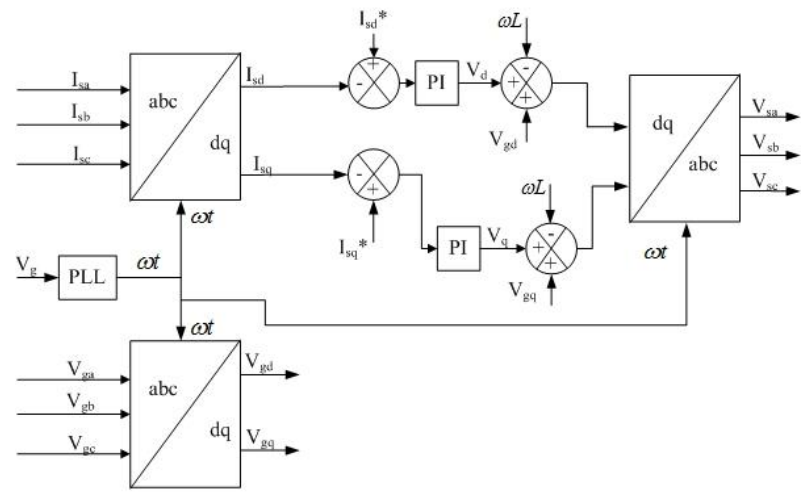

Fig.2. Block diagram of generation of a control signal using rotating reference frame and Type 1 controller.

The grid voltages and inverter currents of the AC circuit are transformed to a synchronousrotating reference frame by Kron's transformation is defined by

$$
\begin{gathered}
f_{a b c}=C_{K} f_{d q o} \\
\text { Where } C_{K}=\sqrt{\frac{2}{3}}\left[\begin{array}{ccc}
\cos \left(\omega_{0} t\right) & \sin \left(\omega_{0} t\right) & \frac{1}{\sqrt{2}} \\
\cos \left(\omega_{0} t-\frac{2 \pi}{3}\right) & \sin \left(\omega_{0} t-\frac{2 \pi}{3}\right) & \frac{1}{\sqrt{2}} \\
\cos \left(\omega_{0} t+\frac{2 \pi}{3}\right) & \sin \left(\omega_{0} t+\frac{2 \pi}{3}\right) & \frac{1}{\sqrt{2}}
\end{array}\right]
\end{gathered}
$$

\section{IV.GENERATION OF SPWM}

The basic idea to produce PWM Bipolar voltage switching signal is shown in the Fig. 3.It comprises the comparator i.e used to compare between the reference voltage waveform $V_{s x}$ (where $\mathrm{x}$ is $\mathrm{a}, \mathrm{b}$ or $\mathrm{c}$ ) and triangular carrier signal $V_{c}$ and produces bipolar switching sequence[2]. This scheme is applied to three phase inverter circuit. In inverter upper switches are turned $\mathrm{ON}$ when the $V_{s x}$ is greater than $V_{c}$ and complimentary switches (lower switches of same leg) are turned OFF. Frequency of reference signal is a fundamentalfrequency $(50 \mathrm{~Hz})$ and carrier signal is switched for high frequency $(40 \mathrm{KHz})$.

The MATLAB/SIMULINK model of SPWM is as shown in Fig.4.

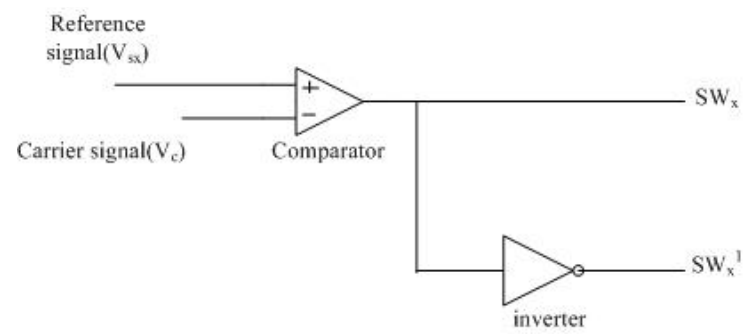

Fig.3.Block diagram of generation of a SPWM.

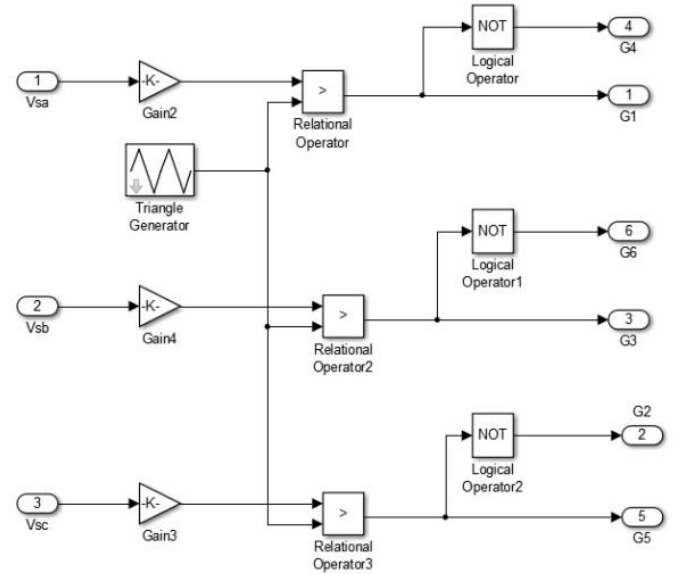

Fig.4. MATLAB/SIMULINK model of a SPWM

\section{ANALYSIS OF EFFECTIVENESS OF CURRENT CONTROLLER IN GRID TIE INVERTER}

It is a well-known fact that, converter output voltage lags the bus voltage to absorb active power and magnitude of converter output voltage is less than bus voltage to absorb the reactive power from the bus. To supply active power to grid it is desired to control the converter output voltage to lead the bus voltage and it can also supply reactive power when the converter output voltage magnitude is greater than bus voltage.

Case 1: Absorption of active power and reactive power When the active current $\left(\mathrm{I}_{\mathrm{sq}}\right)$ is positive and reactive current $\left(\mathrm{I}_{\mathrm{sd}}\right)$ is negative. Inverter current lags the grid voltage. Magnitude of inverter output voltage $\left(V_{s}^{i}\right)$ is less than the magnitude of the grid voltage $\left(\mathrm{V}_{\mathrm{g}}\right)$ and also inverter voltage lags the grid voltage by an angle $\alpha$. Hence inverter absorbs both active and reactive power from the grid. Phasor representation of grid voltage and inverter output voltage is as shown in Fig.5.

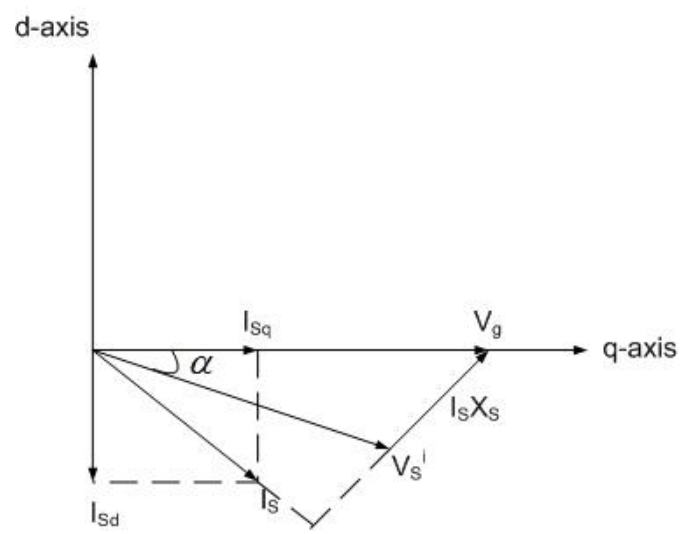

Fig.5. Absorption of active power and reactive power

Case 2: Absorption of active power and supply of reactive power 
When both the active current $\left(\mathrm{I}_{\mathrm{sq}}\right)$ and reactive current $\left(\mathrm{I}_{\mathrm{sd}}\right)$ from the grid. Phasor representation of grid voltage and arepositive, inverter current leads the grid voltage. inverter output voltage is as shown in Fig.8.

Magnitude of inverter output voltage is greater than the magnitude of the grid voltage. Inverter output voltage $\left(\mathrm{V}_{\mathrm{s}}{ }^{\mathrm{i}}\right)$ lags the grid voltage $\left(\mathrm{V}_{\mathrm{g}}\right)$ by an angle $\alpha$. Hence inverter absorbs the active power from thegrid and supplies the reactive power to the grid.Phasor representation of grid voltage and inverter output voltage is as shown in Fig.6.

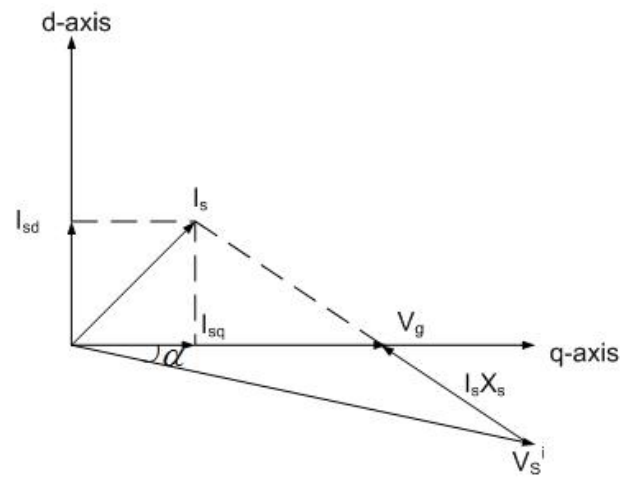

Fig.6. Absorption of active power and supply of reactive power.

Case 3: Supply of both active and reactive power

When the active current $\left(\mathrm{I}_{\mathrm{sq}}\right)$ is negative and reactive current $\left(\mathrm{I}_{\mathrm{sd}}\right)$ is positive, inverter current leads the grid voltage. Magnitude of inverter output voltage is greater than themagnitude of the grid voltage and also inverter output voltage $\left(\mathrm{V}_{\mathrm{s}}^{\mathrm{i}}\right)$ leads the grid voltage $\left(\mathrm{V}_{\mathrm{g}}\right)$ by an angle $\alpha$ Hence inverter supplies both active andreactive power to the grid. Phasor representation of grid voltage and inverter output voltage is as shown in Fig.7.

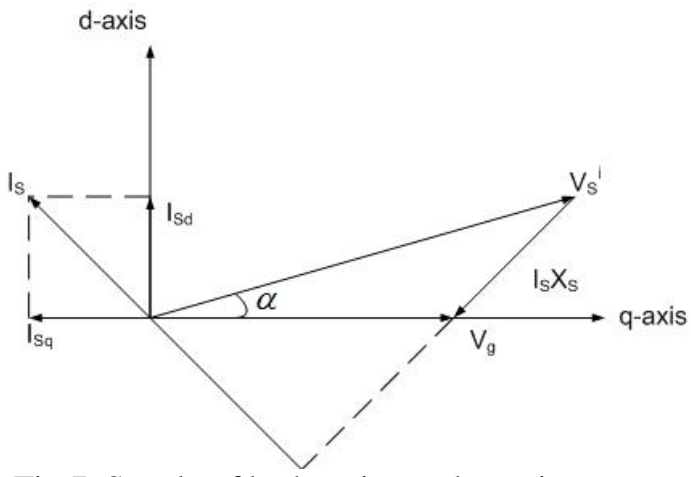

Fig.7. Supply of both active and reactive power

Case 4: Absorption of reactive power and supply of active power

When both the active current $\left(\mathrm{I}_{\mathrm{sq}}\right)$ and reactive current $\left(\mathrm{I}_{\mathrm{sd}}\right)$ is negative. Inverter current lags the grid voltage. Magnitude of inverter output voltage $\left(V_{s}^{i}\right)$ is less than the magnitude of the grid voltage $\left(\mathrm{V}_{\mathrm{g}}\right)$ and also inverter voltage leads the grid voltage by an angle $\alpha$. Hence invertersupplies the active power to the grid and absorbs the reactive power

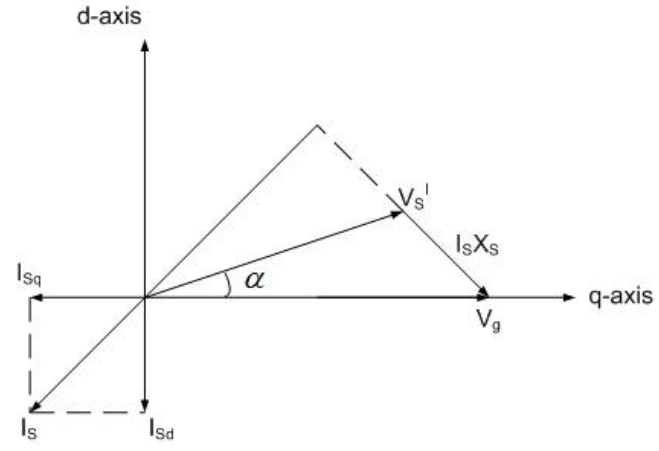

Fig.8. Absorption of reactive power and supply of active power.

\section{VI.SIMULATION RESULTS}

Case 1: Absorption of active power and reactive power When $\mathrm{I}_{\mathrm{sq}}=(+)$ ve and $\mathrm{I}_{\mathrm{sd}}=(-) \mathrm{ve}$, grid voltage and Inverter current v/s time is as shown in Fig.9. Active power and reactive power v/s time is as shown in Fig.10.

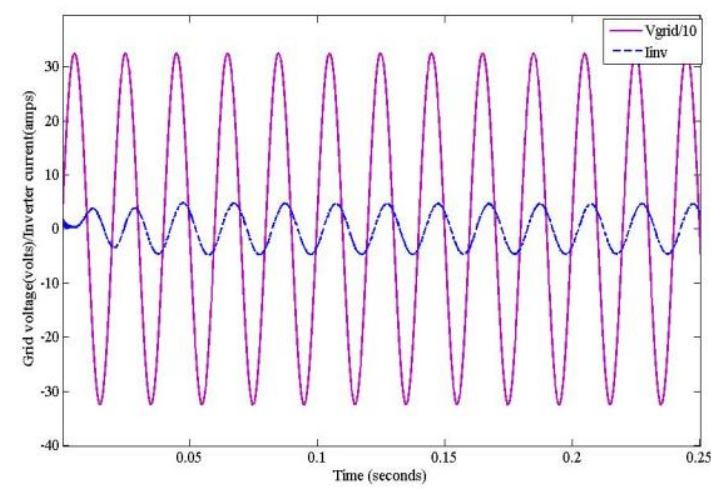

Fig.9. Grid voltage and Inverter current v/s time

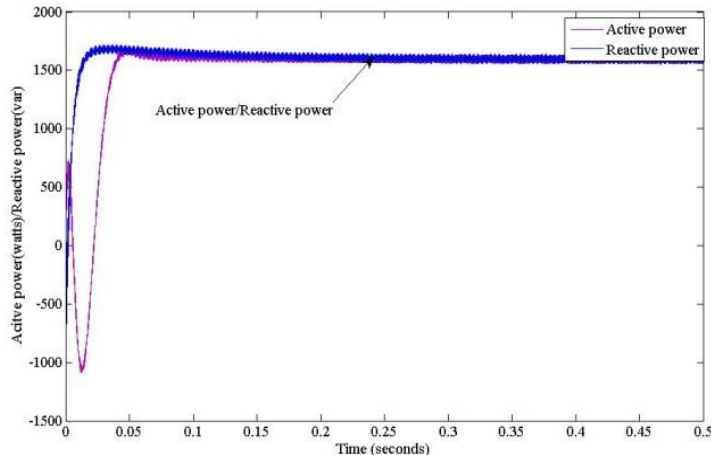

Fig.10. Active power and Reactive power v/s time

Case 2: Absorption of active power and supply of reactive power 
When $I_{s q}$ is $(+)$ veand $I_{s d}(+) v e$,grid voltage and Inverter current v/s time is as shown in Fig.11. Active power and reactive power v/s time is as shown in Fig.12.

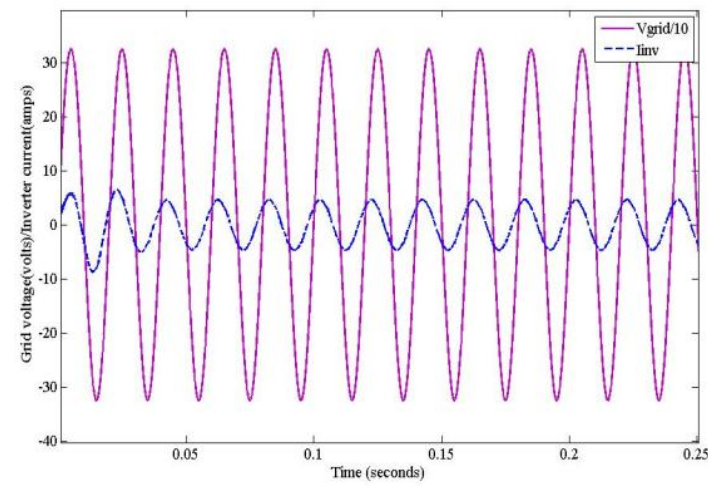

Fig.11. Grid voltage and Inverter current v/s time

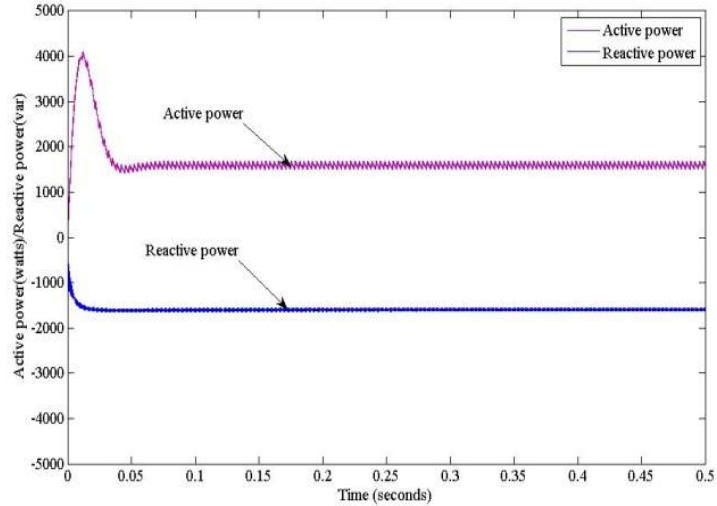

Fig.12. Active power and Reactive power v/s time

Case 3: Supply of both active and reactive power When $I_{s q}$ is (-)veand $I_{s d}(+) v e$, grid voltage and Inverter current v/s time is as shown in Fig.13. Active power and reactive power v/s time is as shown in Fig.14.

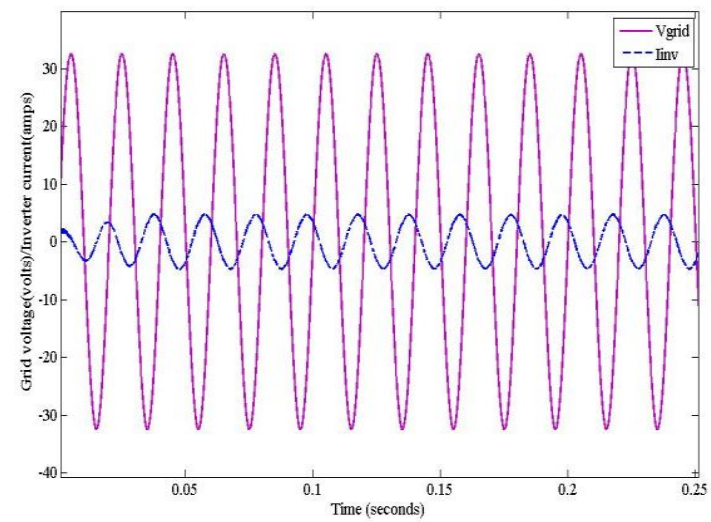

Fig.13. Grid voltage and Inverter current v/s time

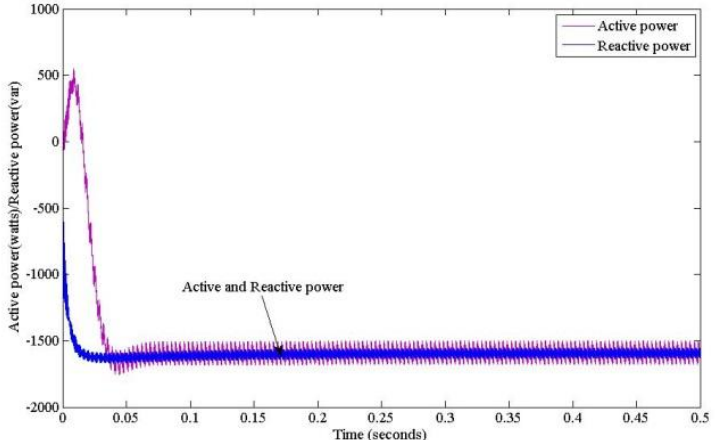

Fig.14. Active power and Reactive power v/s time

Case 4: Absorption of reactive power and supply of active power When $I_{s q}(-)$ veand $I_{s d}$ is (-)ve,grid voltage and Inverter current v/s time is as shown in Fig. 15. Active power and reactive power v/s time is as shown in Fig. 16.

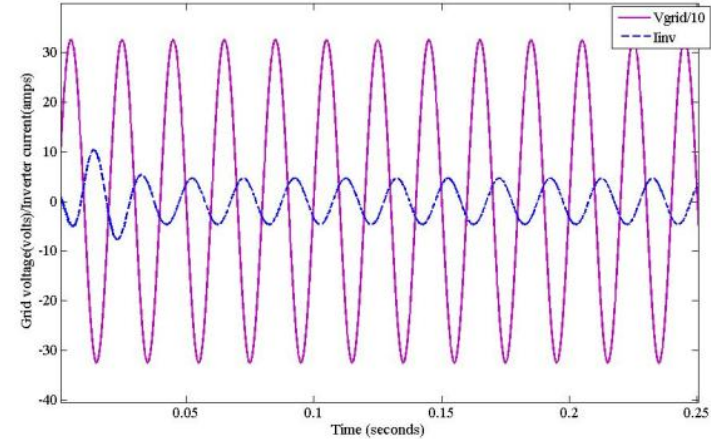

Fig.15. Grid voltage and Inverter current v/s time

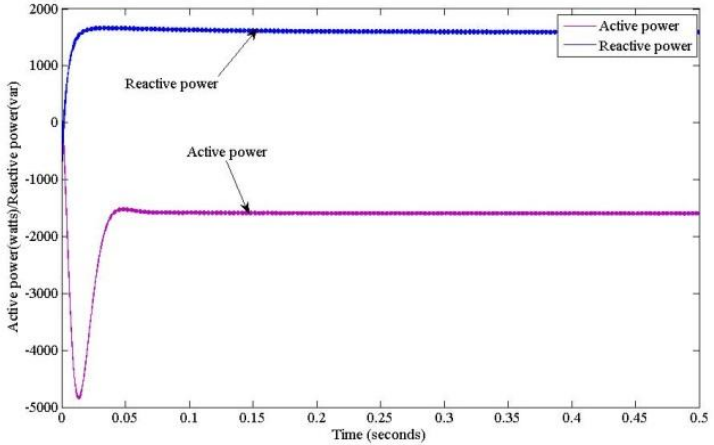

Fig.16. Active power and Reactive power v/s time

\section{CONCLUSION}

The paper explains design of synchronous reference frame current controller of a three phase grid tie inverter. The designed controller effectively controls the active and reactive powerinteraction between the grid and inverter. The simulation results demonstrate the effectiveness of controller ensuring the desired active and reactive power interaction between the grid and inverter. 


\section{ACKNOWLEDGMENT}

Authors gratefully acknowledge the support received from NMAM Institute of Technology,Nitte Education Trust and VTU,Belgavi in carrying out the research work.

\section{REFERENCES}

[1] K.R. Padiyar, "FACTS Controllers in Power Transmission and Distribution", India:New Age International, 2012.

[2] Bimal K.Bose, "Modern Power Electronics and AC drives",2008.

[3] Disha, Chaitra L.,Suryanarayana K,Nagesh Prabhu, "Modelling of rotating referenceframe control of transformerless single phase grid tie inverter", International Journal of Innovative Research in Sceince ,engineering and technology(ISO:3297:2007, Certified Organization) Volume 5, special Issue 9, May 2016.

[4] K. R. Padiyar, Senior Member, IEEE, and Nagesh Prabhu, "Design and Performance Evaluation of Subsynchronous Damping Controller With STATCOM",IEEE TRANSACTIONS ON POWER DELIVERY, VOL. 21, NO. 3, JULY 2006.

[5] J. S.Keyur R. Kinariwala1, Piyush K. Patel2, Kapildev N. Arora3, , "Compensation of Reactive Power Using STATCOM in Distribution Network International Journal of Emerging Technology and Advanced Engineering",Website: www.ijetae.com(ISSN 2250-2459, ISO 9001:2008 Certified Journal, Volume 5, Issue 3, March2015)

[6] S.K.Sethy, J.K.Moharana, "Design, Analysis and Simulation of Linear Model of aSTATCOM for Reactive Power Compensation with Variation of DC-link Voltage",International Journal of Engineering and Innovative Technology (IJEIT) Volume2, Issue 5, November 2012.

\section{BIOGRAPHIES}

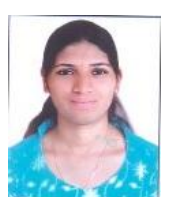

Jayashree $M$ received her B.E degree in Electrical and Electronics Engineering from B.M.S Evening College of Engineering, Bangalore, Karnataka, India in 2015.Currently she is pursuing her M.Tech. in Power Electronics at NMAM Institute of Technology, Karnataka, India. Her areas of interest include Power electronics and Power systems.

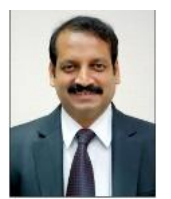

Nagesh Prabhu received the Dipl. Elect. Eng. Degree from Karnataka Polytechnic, Mangalore, India in 1986.He graduated in Electrical Engineering from the Institution of Engineers, India, in 1991. He received M.Tech. degree in power and energy systems from Karnataka Regional Engineering College, Surathkal, India (presently N.I.T. Karnataka) in 1995 and the Ph.D. degree from the Indian Institute of Science, Bangalore in 2005. Currently, he is Professor and Head of Electrical and Electronics Engineering at NMAM Institute of Technology, Nitte, India. He has served in the academic field since 1986. His research interests are in the area of power system dynamics and control, HVDC and FACTS, and custom power controllers. Dr. Prabhu is a member of IEEE, life member of the Indian Society for Technical Education and Indian Society of Lighting Engineers. 